\title{
Corpo de Afetos: entre o apego emocional e o movimento dançado ${ }^{\star}$

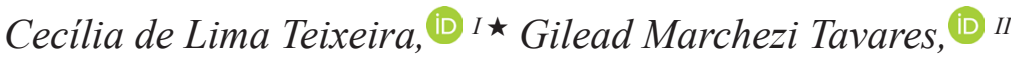 \\ ${ }^{I}$ Universidade de Lisboa, Lisboa, Portugal

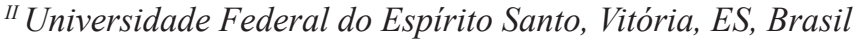

\begin{abstract}
Resumo
O afeto é experienciado pelo bailarino em um nível energético básico: uma necessidade de respirar - inspirar o mundo no corpo e expirar o corpo no mundo. Neste movimento de afeto, o bailarino experiencia um processo de transformação corporal como necessidade vital. Este estudo confronta a percepção sensório-somática do afeto como força de movimento experienciada pela prática da dança, com o afeto compreendido como vínculo emocional entre indivíduos estudado por um campo da psicologia do desenvolvimento. Atribuindo voz ao conhecimento da dança e usando a teoria de Metáforas Cognitivas de Lakoff e Johnson, procura-se aprofundar a origem do sentido de afeto e compreender como ocorre a sua transferência de sentido entre a dança e a psicologia. Em ambos campos, o afeto revela-se como força de sobrevivência, porém, a dança compreende o afeto no nivel pré-pessoal, como força da relação corpo-mundo, enquanto uma parte da psicologia do desenvolvimento entende o afeto no nível de necessidades de um corpo já subjetivado.
\end{abstract}

Palavras-chave: afeto; intensidade; movimento; percepção sensório-motora; transformação.

\section{The Body's Affection: between emotional attachment and danced movement}

\begin{abstract}
Affect is experienced by the dancer at a basic energetic level: a need to breathe-breathe in the world through the body and breathe out the body into the world. Through this movement of affect the dancer experiences a bodily transformation process as a vital need. This study confronts the sensory-somatic perception of affect as a force of movement experienced by the practice of dance, with the notion of affection taken as an emotional bond between individuals studied by developmental psychology. By giving voice to dance knowledge and by using the theory of Cognitive Metaphors of Lakoff and Johnson, it seeks to deepen the origin of the sense of affection and to understand how its transference of meaning between the dance and psychology occurs. In both fields, affection reveals itself as a survival force. However, dance perceives affection at a pre-personal level, as a force of the body-world relation, whereas developmental psychology perceives affection at a conscious level, i.e. at the level of a body that has already passed through a process of subjectivation.
\end{abstract}

Keywords: affection; intensity; movement; sensorimotor perception; transformation.

\section{Introdução}

A origem deste artigo deriva de vários anos de trabalho intenso como bailarina e coreógrafa, ao longo dos quais a necessidade de sentir o corpo se vem revelando enquanto força de afeto. Afeto surge como uma necessidade corporal de incorporar e desincorporar, de expandir e contrair, de absorver e expelir, e manifesta-se como força/ desejo intrínseco ao corpo vivo, que provoca movimento.

Por meio da dança descobri uma experiência de corpo em estado de intensa vibração, animado e excitado por uma força/necessidade de afetar e ser afetado (ESPINOSA, 1983). Este artigo resulta de uma investigação sobre como essa compreensão, que se faz na vivência corpórea dos afetos, se relaciona com a noção de afeto descrita pela filosofia e pela psicologia.

O que é esta sensação de afeto que se sente no pulso do corpo, na emoção e no pensamento? Como ocorre a passagem de sentidos entre afeto enquanto fenômeno so-

\footnotetext{
^Fontes de financiamento e apoio: Fundação para a Ciência e a Tecnologia FCT (Portugal).

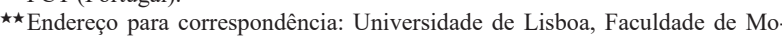
tricidade Humana. Instituto de Etnomusicologia - Centro de Estudos em Música e Dança. Estrada da Costa, 1499-002 - Cruz Quebrada, Dafundo, Lisboa, Portugal.E-mails: ceciliateixeira@fmh.ulisboa.pt, gileadmt.2014@gmail.com Os dados completos das autoras encontram-se ao final do artigo.
}

mático intrínseco ao pulsar do corpo na dança, e afeto enquanto um vínculo emocional de relação entre indivíduos explicada pela teoria de apego da psicologia?

\section{Metáforas Cognitivas: a nossa capacidade intrínseca} de trans-versar sentidos e atravessar domínios do saber

\footnotetext{
"A metáfora, sendo o instrumento de uma linguagem não lógica, pode tocar, isto é, explicar (ou provar) coisas que a linguagem lógica não toca nem explica” (TAVARES, 2006, p. 112).
}

Como é amplamente estudado e defendido pelas ciências cognitivas e neurociências, a gênese do conhecimento e da capacidade de articular pensamento advém do sentido experiencial intrínseco à percepção somática e sensório-motora (DAMÁSIO, 2000, 2003, 2010; GIBBS, 2005; GIBSON, 1966; EDELMAN, 1992, MATURANA; VARELA, 1980). Deste modo, também o sentido percebido através da linguagem verbal terá de ser desenvolvido com base no nosso sentido experiencial. A construção de sentidos articulados por meio de qualquer sistema linguístico e a própria capacidade de abstração dele derivado terá de ser fundado na experiência sensório-somática. A capacidade metafórica vem sendo gradualmente reconhecida por alguns cientistas e acadêmicos 
como o modo pelo qual é feita a transferência de sentido gerado no domínio experiencial e sensório-somático para o sentido projetado em conceitos linguísticos relativos a domínios abstratos.

O reconhecido neurocientista Robert Sapolsky (2011) refere-se à capacidade metafórica como uma aptidão funcional característica da espécie humana, ${ }^{1}$ demonstrando que é esta capacidade que nos torna aptos a transferir conceitos somáticos e sensório-motores para âmbitos abstratos e morais. Sapolsky revela a metáfora como uma disposição intrínseca ao nosso funcionamento orgânico a qual faz com que os valores derivados da experiência sensório-somática sejam transferidos para um plano conceitual abstrato, sendo a partir desta aptidão que o ser humano consegue construir um sistema simbólico e abstrato. Por exemplo, diz o cientista, quando contemplamos repugnância moral ou ética, é ativada a mesma parte do cérebro que quando estamos comendo ou cheirando algo que nos repugna. $\mathrm{O}$ cérebro concebe este âmbito abstrato através de um modo muito concreto, literalmente ligado à experiência corporal e sensorial; daí os atos éticos ou morais estarem invariavelmente associados a conceitos relacionados com noções de pureza, sujidade, repulsa, proximidade etc. Outro exemplo de transferência metafórica é o âmbito de sensações físicas como modo de avaliar personalidade. Sensações presentes, por exemplo, em conceitos como rigidez (personalidade rígida ou flexível), temperatura (personalidade quente ou fria), firmeza (personalidade segura ou vacilante, fixa ou móvel), textura (personalidade suave ou áspera) etc. Sapolsky menciona também a capacidade de empatia e personificação como capacidades associadas à transferência metafórica intrínseca ao nosso funcionamento. Empatia permite fazer uma transferência entre o domínio do sentimento do (como alguém próximo), mas, ainda mais, permite transferir sentimento para o domínio do outro enquanto entidade abstrata, como, por exemplo, um grupo de pessoas ou animais desconhecidos ou imaginários. É a mesma parte do cérebro que atribui o sentimento, não apenas do próprio sujeito em estado de dor, mas também da imaginação de dor no outro. Personificação permite transferir características do domínio humano para outros domínios, como outros domínios vivos, materiais ou mesmo entidades abstratas. Sapolsky (2011) salienta:

This is an absolutely wild way in which this metaphor stuff, as abstract as you can get, is inadvertently being processed by the brain in the most concrete literal ways and outcomes all sorts of ways in which we are suddenly being shaped by these phenomena. And a lot of researchers in the field of neurobiology of moral behaviour note that essentially what we do with our conscious decision making is justify the intuition and visceral responses we already had (transcrição da autora).

\footnotetext{
Nesta conferência, Sapolsky discute a capacidade metafórica associada à capacidade simbólica e à abstração como algo que distingue a espécie humana. A minha referência a este discurso não pretende dar ênfase à questão de distinção da espécie humana de outras espécies animais, mas sim ao modo como o autor aborda a natureza da metáfora.
} próprio sujeito para o domínio do sentimento do outro

A noção de "Metáforas Cognitivas" desenvolvida por Lakoff e Johnson $(1980,1999,2003)$ clarifica como a noção de metáfora, ao revelar precisamente essa capacidade de transferir sentidos do seu domínio originário (sensório-somático) para domínios secundários, abstratos e imaginativos do pensamento, assinala não meramente uma figura de estilo poética da linguagem, mas constata uma capacidade cognitiva funcional, essencial ao pensamento abstrato. Ou seja, o sistema conceitual construído pela nossa articulação verbal de pensamento é criado principalmente através de um processo metafórico. A formação de conceitos formais pela nossa mente deriva principalmente do domínio sensório-motor, sendo que o mecanismo metafórico é um mecanismo cognitivo intrínseco que permite a transferência da experiência e imagens incorporadas pelo domínio sensório-motor para o domínio conceitual do pensamento verbal. Deste modo, os autores acima citados (1980, p. 477) consideram que o sistema linguístico é, de modo geral, formado por conceitos emergentes ou primários e conceitos secundários. Conceitos Primários, ou Emergent Concepts, são todos os conceitos fundados nas correlações sistemáticas com a experiência, ou seja, que se correlacionam diretamente com a experiência, dependendo de uma sensação sensório-motora e de imagens multissensoriais. São conceitos entendidos de um modo imediato, sem necessidade de uma associação metafórica, como, por exemplo, as noções de: cima, baixo, abrir, cair, agarrar, torcer, próximo, distante, quente, vermelho, aqui, ali, pesado, leve etc. Esta teoria indica que são estes conceitos, diretamente derivados da experiência e da sensação sensório-motora, que constituem a base estrutural do pensamento conceitual. Os conceitos secundários são todos aqueles que não surgem diretamente da experiência sensório-motora, mas que são concebidos por meio de uma translação metafórica, ou seja, o seu significado é construído através do processo cognitivo metafórico que vai buscar sentido nos conceitos emergentes. Por exemplo:

- Concebemos a noção de tempo como um movimento. Quando pensamos em tempo, inerentemente e inconscientemente o associamos a uma passagem: o tempo passa rápido, o tempo voa, o tempo parou.

- Concebemos a noção de alegria associada a uma postura, uma orientação corporal, um estado energético. Quando pensamos em alegria, inerentemente a associamos a uma sensação de abrir, uma direção para cima.

- Concebemos a noção de importante como grande.

- Concebemos a noção de dificuldade como peso.

- Concebemos a noção de organização como uma estrutura física.

- Concebemos a noção de conhecimento essencialmente como ver, agarrar, manipular.

Fractal, Rev. Psicol., v. 32 - n. 1, p. 99-107, 2020 
- Concebemos a noção de afeto associada à temperatura. Dizemos que os latinos são quentes e os alemães frios.

Assim sendo, diria que há aqui uma reversão no modo de conceber sentido, pois, por exemplo: não é o quente que é uma metáfora para afeto, mas é o afeto que é concebido através da noção “quente". Ou seja, é a partir da capacidade de transposição, transmutação de sentido (a que chamamos de metáfora), que conseguimos projetar o sentido de conceitos emergentes (derivados dos domínios sensório-somáticos e experienciais) para edificar sentido de conceitos abstratos relativos a outros domínios da nossa capacidade imaginativa e de abstração.

Assim, como que em resposta à citação inicial deste capítulo, de Gonçalo Tavares (2006), os autores confirmam:

The fact that abstract thought is mostly metaphorical means that answers to philosophical questions have always been, and always will be, mostly metaphorical [...] Metaphorical thought is the principal tool that makes philosophical insight possible" (LAKOFF; JOHNSON, 1999, p. 7).

Esta capacidade de transferência inerente ao processo cognitivo vem corroborar a teoria da cognição corporificada, revelando o seu modo intrínseco de funcionamento, através do qual concebemos sentidos e pensamentos. É com base nesta capacidade de transferência inerente ao processo cognitivo que me fundamento para aprofundar como a noção de afeto atravessa o seu domínio sensório-motor experienciado na dança e o seu domínio emocional abordado pela psicologia desenvolvimentista.

\section{Os sentidos sensório-motores com que construímos o conceito de afeto}

Ao considerar esta transferência de sentido de um domínio para outro é essencial reparar que, muitas vezes, os conceitos secundários não têm apenas um conceito emergente associado, mas são compreendidos como uma composição dinâmica de várias sensações sensório-motoras e de um intrincado experiencial desenvolvido ao longo da vida.

Portanto, a noção de afeto não é associada somente a um domínio sensorial, mas relaciona-se com vários domínios: temperatura (quente e frio), distância (perto ou longe); com uma experiência agradável de tato (associado a carícias, usualmente leve e lento); com formas arredondadas; com texturas fofas e macias, e até com determinadas zonas corporais, como o ventre.

Para mais, embora o sentido de conceitos secundários seja composto de percepções básicas de sentido sensório-motor e experiencial, estas composições de sentido têm uma natureza dinâmica e plástica. Assim, por exemplo, a minha percepção de afeto não será exatamente igual à de outros, porque a minha experiência de quente, perto, redondo, fofo e de colo tem nuances particulares, diferentes de qualquer outra. É ainda importante realçar que a relação com as percepções sensoriais ao longo da vida vão se alterando de forma sutil, quase indescritível, e, como tal, também a compreensão de conceitos.

Fractal, Rev. Psicol., v. 32 - n. 1, p. 99-107, 2020
Por exemplo: na composição da minha noção de afeto, foco principalmente o sentido de "perto", enquanto que outra pessoa poderá focar particularmente o sentido de "quente". Ou ainda, por exemplo, no passado o meu sentido de afeto compunha-se majoritariamente na percepção de "colo", e hoje pode estar mais focado na sensação de "carícia de uma mão".

Então, o nosso processo cognitivo de construção de sentido se dá a partir de padrões de incorporação dinâmicos, de experiência multimodular e recorrente, que estabelece estruturas de entendimento e racionalização. $\mathrm{O}$ estudo que consiste em estruturar esta base de padrões recorrentes de onde se formam os sentidos é intitulado Image Schemata.

A schema consists of a small number of parts and relations, by virtue of which it can structure indefinitely many perceptions, images, and events. Image schemata operate at a level of mental organization that falls between abstract propositional structures, on the one side, and particular concrete images on the other (JOHNSON, 1990, p. 29).

Image Schemata estuda um padrão recorrente, forma e regularidades dessas experiências significativas. Contudo, como o autor demonstra, "it is important to recognize the dynamic character of image [embodied] schemata as structures for organizing our experience and comprehension" (JOHNSON, 1990 p. 29). Os padrões de formação de sentido são fundamentalmente compostos através de imagens multimodais, ou seja, são fundamentalmente gerados através do sentido emergente dos nossos movimentos, manipulação de objetos e interações corporais e sensíveis - porém estes geradores principais de sentido são também influenciados e esquematizados pela própria experiência incutida pela lógica inerente a cada linguagem e pelo contexto histórico e cultural em que vivemos.

\section{A noção de afeto na teoria do apego da psicologia}

Afeto é descrito nos dicionários gerais como um elemento do qual todas as manifestações emocionais são essencialmente compostas. No glossário online de psiquiatria, ${ }^{2}$ afeto é relacionado com um estado emocional imediato, reconhecido subjetivamente pela pessoa e objetivamente por outros. No artigo The nature of love, Harlow (1958) equipara o sentimento de afeto com amor, proclamando que, apesar da sua natureza íntima e pessoal, o amor ou afeto é uma faceta predominante nos humanos, e, como tal, não deverá ser desconsiderada como tópico de pesquisa experimental.

A teoria do apego afetivo (Attachment Theory) foi originalmente desenvolvida pelo psicanalista britânico John Bowlby (1907-1990) como uma teoria abrangente sobre a natureza das ligações afetivas da infância, em que apego refere-se a um vínculo afetivo entre o bebê e a figura de apego (um cuidador, geralmente pensado como a mãe). Embora hoje em dia a importância do apego afetivo no desenvolvimento infantil se possa considerar como uma noção que faz parte do senso comum, na altura dos estudos iniciais de Bowlby vários psicanalistas defendiam que as manifestações extremas de stress por parte de crianças

${ }^{2}$ Disponível em: http://www.priory.com/gloss.htm. 
órfãs ou sem figura de apego eram meramente sinais imaturos de mecanismos de defesa, operados para reprimir a dor emocional (FRALEY; GILLATH; KARANTZAS, 2016). O trabalho de Bowlby ofereceu outra perspectiva sobre esta questão do apego afetivo. Baseado em estudos etológicos e no trabalho de campo desenvolvido com crianças órfãs do pós-guerra, este cientista demonstrou que tais comportamentos de apego são comuns a uma grande variedade de espécies mamíferas, tendo uma função evolutiva. Inclusive, aquilo que chamou de "sistema de comportamentos de apego" é um fenômeno que se vai desenvolvendo através de um processo de seleção natural para aferir proximidade à figura primária de apego, e assim assegurar a sobrevivência (como, por exemplo, a proteção contra predadores, alimentação, exploração do ambiente etc.) até a idade de reprodução.

De modo geral, a concepção de apego afetivo é abordada por Ainsworth e Bowlby (1991) como sendo um profundo e duradouro vínculo emocional que relaciona uma pessoa com outra através do tempo e espaço. Bowlby (1969) caracteriza comportamentos específicos de relações de apego em crianças, as quais procuram proximidade com a figura de apego quando ameaçadas ou perturbadas. Por sua vez, o comportamento de cuidado parental de adultos em relação a crianças envolve uma atenção e reação sensitiva apropriada às necessidades da criança. Os padrões de apego desenvolvidos desde a primeira infância levariam a modelos internos de funcionamento, que guiariam as percepções individuais, emoções, pensamentos e expectativas de relacionamentos posteriores.

$\mathrm{Na}$ sua experiência com macacos bebês cujas mães biológicas foram substituídas por "mães inanimadas", Harlow (1958) e Harlow e Zimmermann (1959) demonstraram que esta relação de apego afetivo é em parte desenvolvida como resultado de uma satisfação de determinadas necessidades primárias, como a necessidade de sucção e alimentação, conforto e contato físico (especificamente relacionados com a manutenção de temperatura corporal e contato com superfícies macias e fofas). Contudo, apesar de estes macacos terem desenvolvido uma relação de apego afetivo com objetos inanimados que lhe satisfaziam necessidades básicas de alimentação, proteção e identificação, mais tarde, na idade adulta, eles irão desenvolver padrões de comportamento atípicos e desajustados, sendo que, quando as fêmeas de "mães inanimadas" se tornaram elas próprias mães, revelaram comportamentos de negligência e abuso para com as crias.

Estes primeiros estudos sobre o apego vêm enfatizar a natureza afetiva humana como uma necessidade primária de sobrevivência. Simultaneamente induzem novas questões e trazem novo foco à necessidade e interesse em aprofundar conhecimentos sobre os fenômenos de afeto e emoção.

Bronfenbrenner e Evans (2000), impulsionados pelas novas descobertas científicas dos últimos anos, compreendem que o conceito de desenvolvimento na psicologia deixou de poder ser abordado meramente como um processo linear, esquemático, passando a ser abordado como um fenômeno mais complexo de interações multidimen- sionais. Dentro dessa abordagem, recentes estudos sobre o apego afetivo vêm realçar a natureza do afeto como um processo interativo do desenvolvimento. Processo este em que a capacidade de sobrevivência é perspectivada como uma dinâmica de inter-relações entre níveis físicos, emocionais e cognitivos. Este "olhar para a vinculação humana em multiníveis ecologicamente situados e embutidos em um sistema dinâmico de redes de relações ocasionou maior compreensão da complexidade do fenômeno do apego" (PONTES et al, 2007, p. 76). Resumindo, atualmente o desenvolvimento do apego afetivo precisa ser considerado como um processo de inter-relação entre necessidades de sobrevivência física (como a alimentação e a proteção) e necessidades primárias de identificação e reconhecimento (que se manifestam primordialmente na procura de contato físico e na urgência em seguir e copiar movimentos e comportamentos). Este processo interativo resultará num desenvolvimento multidimensional entre as capacidades de aprendizagem cognitiva, comportamental e de regulação de emoções.

Nesse campo da psicologia, pode-se entender que as sensações sensório-motoras são uma fundação para o afeto, porém perspectivando sempre um vínculo emocional que relaciona uma pessoa com outra. Vínculo este a partir do qual se satisfazem necessidades de sobrevivência física e necessidades primárias de identificação e reconhecimento.

\section{O movimento de afeto do corpo dançado}

Através da prática da dança e das práticas somáticas a ela associadas, o bailarino desenvolve uma consciência sensorial intensificada do movimento do corpo e do corpo como puro movimento. Como expressam Vera Mantero e José Gil (1998), o corpo em dança é um corpo que se prolonga através dos seus sentidos, uma consciência de corpo que vivencia os seus delírios e pulsões (MANTERO; GIL, 1998). Por meio da prática de intensificação proprioceptiva, o bailarino percebe o corpo como um estado de vibração constante, um pulsar de micromovimentos vitais. Esses micromovimentos são intrínsecos ao seu processo de equilíbrio homeostático. Processo este que trabalha à procura de equilíbrio sobre a urgência da sua constante renovação, intrínseca ao processo vivo do corpo -o seu processo de manutenção de vida é, pois, um processo de constante transformação. Ao se relacionar essa percepção de um corpo que vibra numa contínua transformação com o processo biológico de equilíbrio homeostático, torna-se então evidente que a percepção do corpo enquanto estado de vibração experienciado pelo bailarino não é algo místico ou transcendental; pelo contrário, é simplesmente uma intensificação perceptiva do corpo no seu processo fisiológico básico de se manter vivo (LIMA, 2013).

É claro que o bailarino não tem uma visão do tipo científica em que visualizaria e identificaria os detalhes do complexo processo biológico de equilíbrio homeostático; o que ele percebe não é um corpo definido, contido sob a superfície da pele, mas sim o movimento de transformação próprio ao seu processo de vida. O que ele vivencia é uma constante nuvem de micromovimentos de vibrações interativas entre o meio interno e o exter- 
no. Ora, este seu movimento de transformação manifesta um outro âmbito de movimento: o movimento de trocas interativas entre aquilo que é considerado um ambiente interno e o ambiente externo. E esta transferência transformadora contínua entre o que é temporariamente interior e exterior revela-se como uma necessidade/força de vida do corpo - uma força de afeto.

$\mathrm{O}$ afeto é experienciado pelo bailarino em um nível energético básico: uma necessidade de respirar - inspirar o mundo no corpo e expirar o corpo no mundo - uma troca energética que alimenta o processo de transformação como processo vital do corpo. Esta necessidade de afeto revela-se como impulso vital, uma força intrínseca ao corpo vivo, que atua num jogo de oposições: sobre o movimento de absorver e expelir, de incorporar o meio ambiente e desincorporar-se do meio ambiente, ou ser incorporado por ele constantemente. A força de afeto abre o corpo ao mundo.

Similarmente, Mantero e Gil (1988) associam a noção de afetividade a uma força de abrir o corpo - "abrir o corpo é afetividade e a afetividade dá uma força extraordinária. Uma força física e uma força de influência. Uma força de influência e uma força de espírito" (MANTERO; GIL, 1998, p. 33). Neste abrir, o corpo intensifica a sua necessidade de ser atravessado pelo mundo, intensifica as suas pulsões de vida.

Tal percepção do corpo, em que a sua condição de vida é a sua própria necessidade de afeto, é uma sensação familiar na dança. A título de exemplo, o coreógrafo Rui Horta (2006) compreende a necessidade de incorporação como uma necessidade artística: "A necessidade que tenho a cada instante de cruzar a pele do outro, entrar. Esta fusão, que significa para mim o amor, significa estar vivo" (HORTA, 2006, p.12). Essa necessidade de fusão que Rui Horta expõe reflete uma interação orgânica intrínseca à natureza permeável do corpo. Para mais, a expressão de trespassar os limites do corpo como um ato de afeto associado ao sentido de estar vivo não é uma mera metáfora linguística, mas traduz a própria natureza de afeto como uma necessidade de incorporação e desincorporação intrínseca ao processo de sobrevivência.

Nos momentos de dança, a necessidade de um fluir energético de afetos torna-se amplificado. O corpo é sentido como um espaço poroso que continuamente se desdobra e se recria por meio de um processo de incorporação e desincorporação entre o seu interior e o exterior. Afeto é fisicamente experienciado como um processo de sobrevivência que surge de uma necessidade de afetar e ser afetado num feedback interativo entre um meio interno e um meio externo. Gera-se um sentido de intensidade: intensifica-se o movimento e a sensação de penetração na matéria do corpo, donde surge uma força de vida. Força essa que, por sua vez, se realimenta dessa intensidade. Assim, a percepção do corpo trespassa o seu limite material para intensificar o seu poder de vida como um processo de afeto - uma necessidade intrínseca e intuitiva de absorver - incorporar o mundo e expelir - desincorporar-se no mundo e ser incorporado por ele. A consciência de corpo torna-se a consciência desse estado fronteiriço em cons- tante movimento. Na intensidade da dança, o bailarino experiencia movimento não apenas como um deslocamento espacial, mas como movimento de transformação, impulsionado pela força do afeto. A força de afeto revela, assim, um sentido paradoxal, no qual se produz um movimento cíclico com duas orientações opostas:

- um vetor de energia de fora para dentro: uma necessidade de absorver, incorporar, integrar;

- um vetor de energia de dentro para fora: uma necessidade de expelir, desincorporar, desintegrar.

Desse modo, o sentido de afeto na dança não se concebe como composição de conceitos sensório-motores emergentes, mas revela-se na vivência e percepção intensificada do movimento, como uma força que instiga o próprio movimento. Afeto revela-se, então, como a força do movimento intensivo inerente à essência transformativa de um corpo animado, e alimenta uma contínua renovação corporal.

\section{A noção de afeto na filosofia como um experienciar pré-pessoal de intensidade}

A noção de afeto na filosofia vem ao encontro da experiência intensiva de movimento na dança.

Apesar de o afeto ser comumente interpretado por meio de uma perspectiva emocional (como um sentimento de ligação ou ternura), etimologicamente a palavra refere-se a uma predisposição para a influência, para receber ou produzir um efeito ou mudança. Esta noção etimológica de afeto está presente no obra de Espinosa (1983), especialmente em seu tratado sobre a "Ética", em que apresenta a capacidade de afetar e de ser afetado no corpo como aquilo que define seu grau de potência. Nesse sentido, o que o filósofo se esforça em demonstrar é que o corpo é definido pelos afetos, ora de modo ativo (capacidade de afetar), ora de modo passivo (capacidade de ser afetado). "The transitive effect undergone by a body in a system - a mobile and open system - composed of the various, innumerable forces of existing and the relations between these forces. Affection is the state of a body in as much as it affects or is affected by another body" (SEIGWORTH, 2005, p. 161).

Brian Massumi (2002) desenvolve esta noção assinalando que o corpo é continuamente influenciado por milhares de estímulos, assimilando-os e revolvendo-os entre si. Desse modo, Massumi concebe afeto como um experienciar de intensidades, a intensidade da força e duração do efeito de estímulos. Tomkins (DEMOS, 1995) ilustra a índole intensiva de afeto estabelecendo um paralelo com os mecanismos da dor. Tal como a dor amplifica a nossa percepção do ferimento, também o afeto vai amplificar a consciência do sentir; sem afeto as emoções não são sentidas porque não têm intensidade. Concomitantemente, tal como Damásio (2003) demonstra, sem sentimentos as decisões racionais tornam-se problemáticas. Assim, Tomkins (DEMOS, 1995) explica que o afeto tem o poder de amplificar a percepção do nosso estado biológico, e desse modo vem influenciar o sentido somático que sustenta a base da consciência. 
Segundo Massumi (2002), apesar de o afeto ser cotidianamente usado como sinônimo de emoção, afeto como intensidade segue uma outra lógica, pertence a uma outra ordem. Tanto o afeto como o estado de intensidade e a emoção como qualificação desse estado são fenômenos incorporados. Porém, intensidade revela-se no puro sentido intrínseco ao processo de incorporação que é então manifestado nas reações autônomas do sistema nervoso, e especialmente na pele. Por isso, o afeto precede a consciência e, desta forma, é uma experiência pré-pessoal, de natureza somática autônoma, irredutível. A emoção é a intensidade dominada, qualificada e reconhecida. É um fixar da experiência através de uma qualidade sociolinguística que, a partir daí, é definida como pessoal e por isso tem um conteúdo subjetivado. $\mathrm{O}$ afeto permanece inconsciente e é estimulado por fatores sobre os quais o sujeito tem pouco controle, na medida em que foi pelos afetos subjetivado, enquanto que as emoções se tornam conscientes. Com isso, temos que a própria consciência é formada por meio dos afetos, que têm o caráter de forjar sentidos, como emoções e sentimentos. Também Eric Shouse (2005) aprofunda essa diferenciação abordando sentimento como uma sensação que foi verificada e confrontada com experiências anteriores. Sentimento e emoção são, por isso, pessoais e biográficos, porque cada pessoa tem um conjunto distinto de sensações prévias. $\mathrm{O}$ que um bebê experiencia não é assimilado como sentimento porque lhe falta ambos, a linguagem e a biografia de referência. Desse modo, o bebê referencia-se na experiência crua de afeto como intensidades somáticas. Shouse (2005) cita Virginia Demos (1995, p. 19), aludindo que: "Affects are comprised of correlated sets of responses involving the facial muscles, the viscera, the respiratory system, the skeleton, autonomic blood flow changes, and vocalizations that act together to produce an analogue of the particular gradient or intensity of stimulation impinging on the organism".

Assim, o bebê, pensado como um corpo, nasce com a capacidade de afetar e ser afetado. Por meio destas manifestações somáticas, o bebê é capaz de expressar a sua natureza afetiva e, a partir dela, formar-se como sujeito com a construção da consciência que se segue à história de afetos por ele experienciados.

\section{$O$ sentido informe da natureza intensiva de afeto}

Este aprofundar da diferença entre o caráter somático de intensidade pré-pessoal de afeto e a natureza mais consciente, biográfica e qualificável da emoção leva-nos a uma outra colocação: enquanto a emoção funciona numa lógica funcional narrativa, a lógica de afeto tem um sentido que não é semanticamente ou semioticamente ordenado.

A vivência de intensidade da percepção de movimento, ao revelar o corpo enquanto estado de transformação, penetra no movimento do tempo, entra-se num paradigma de sentido emergente do movimento fecundo de tempo. Por outras palavras, a vivência de afeto como um fenômeno de intensidade somática penetra no tempo, tornando-o um movimento que se dirige simultaneamente para o eterno e o petrificado. Num fragmento da sua obra
"Fazendeiros do ar", Carlos Drummond de Andrade expressa de modo genial este sentido paradoxal intrínseco à experiência de intensidade: "Eterno é tudo aquilo que dura uma fração de segundo, mas com tamanha intensidade, que se petrifica, e nenhuma força jamais o resgata" (ANDRADE, 2012, p. 43).

Massumi (2002) aprofunda a percepção do movimento fecundo do tempo apreendendo-o como estado de suspensão ou um momento de potencial informe. $\mathrm{Na}$ percepção do corpo como movimento no tempo, experiencia-se um sentido que não é exatamente de passividade, porque está repleto de movimento vibratório e ressonâncias, e também ainda não é atividade, porque o movimento que contém não é um movimento que se reconhece num mundo de objetos ou que se predispõe a uma finalidade exclusiva. O sentido de suspensão surge, assim, como um vivenciar virtual, em que "the virtual is a lived paradox where what are normally opposites coexist, coalesce, and connect" (MASSUMI, 2002, p. 30).

Similarmente, Simondon (2007), ao abordar afeto como a vitalidade gerada pelo potencial de interação do corpo, elucida que a sua natureza somática é uma manifestação pré-pessoal, na medida em que resiste a uma tendência de confinamento a um corpo particular. Desse modo, o afeto manifesta uma dimensão de abertura emergente que não pode ser compreendida em termos de forma, mas como movimento de transformação.

Em suma, a natureza intensiva do afeto é experienciada como uma vivência de um evento virtual, de expressão emergente, que não segue uma lógica linear casual, mas uma lógica paradoxal, uma lógica em que o sentido surge como um ato em suspenso, na capacidade de fundir o formalmente oposto. Logo, a natureza intensiva do afeto concebe e concebe-se sob uma lógica de sentido incipiente cuja natureza foge a uma lógica de confinamento, ou estruturação linear.

Conclusão: Entre o sentido de transformação da intensificação sensorial e a formalização da significação

Tanto na dança como na psicologia desenvolvimentista o afeto exprime uma necessidade de relação sensório-motora indispensável para a vida do organismo. Porém, naquela psicologia, o afeto é concebido como vínculo emocional de ligação entre sujeitos já formados (mãe-bebê, por exemplo), e na dança o afeto é experienciado como força/necessidade de movimento. Como atravessar estes dois campos de compreensão? A natureza de emoção explicada por Damásio (2000) vem elucidar esta questão. Emoções, de acordo com o autor, são coleções de complicadas respostas químicas e físicas a estímulos internos e externos causando mudanças corporais, de modo a regular o equilíbrio homeostático do organismo. Ou seja, são uma composição de movimentos do organismo em reação a estímulos internos e externos. Esta noção de emoção vem tornar claro que, ao intensificar a percepção de movimento, a dança encontra uma força que instiga o próprio movimento de relação corpo-mundo. $\mathrm{O}$ afeto revela-se, assim, como uma força pré-pessoal, e é experienciada não como uma necessidade pessoal, mas 
como necessidade de animar o corpo, uma força inerente ao corpo enquanto estado de movimento. Já a psicologia parece não considerar o movimento intrínseco ao formar o corpo, mas aborda outro nível de afeto em que o corpo é considerado como algo já concretizado, como um indivíduo. $\mathrm{O}$ afeto seria então um vínculo a outro corpo gerado por emoções, ou seja, gerado por sentimentos intensos da composição de movimentos internos.

Entretanto, podemos compreender, com a ajuda de Tristão (2015), que a psicologia desenvolvimentista pode contribuir de modo importante se alinharmos algumas ideias do trabalho de Bowlby à filosofia espinosista no que se refere ao vínculo afetivo.

Desse modo, voltando-nos para as ideias do autor [Bowlby], podemos dizer que a criança, desde o nascimento, precisa construir um vínculo (o apego) com uma figura humana. Esse vínculo é, ele próprio, o "mundo social”, nosso elo de ligação, que está sempre em feitura. Ele fala de uma relação de confiança e de presença ativa/afetiva. Entendemos essa relação como uma relação de proximidade subjetivo-afetiva que favorece a constituição de uma zona comum e de confiança por onde circulam os fluxos de diferenciação que conferem liberdade aos processos de individuação. Tal zona comum deve ser construída cotidianamente. Ela nunca está pronta, finalizada, mas, ao mesmo tempo, quanto mais a experimentamos, mais potentes ficamos para a sua construção. Dessa forma, entendemos a importância de sua vivência na infância (TRISTÃO, 2015, p. 99).

De todo modo, a passagem do sentido de afeto enquanto relação emocional e enquanto estado de intensidade sensório-somática depara-se com uma dificuldade no nível da linguagem formal e do sentido de significação. Os vínculos emocionais são confinados a um corpo e funcionam segundo uma lógica funcional narrativa que se pode definir e, como tal, têm tendência a formar-se e esgotar-se na sua definição. Ao passo que o corpo tem uma lógica própria que não pode ser completamente capturado na linguagem; portanto, o afeto, no puro sentido intrínseco ao processo de incorporação, não tem um vocabulário cultural ou teórico específico. Esta problemática na passagem do sentido de afeto propõe um modo de partilha de sentidos que não se alcança tendo apenas a linguagem (abstrata, formal) como meio único de comunicação. Para tal, propomos aqui duas abordagens como exercícios de incorporação cognitiva de afeto, as quais intentam potenciar esta transferência entre modos de conceber o sentido do fenômeno de afeto:

A) A primeira abordagem alude à importância das práticas sensório-motoras. Neste sentido Shouse (2005) salienta que, ao desenvolver consciência desta diferenciação comunicativa, o poder de afeto reside exatamente no fato de que, ao ser transmissível de um modo sensorial, torna-se por isso mais direto que as emoções e os sentimentos, revelando ser uma poderosa e delicada força biológica e sociocultural com amplos potenciais por explorar. Esta é uma linguagem informe que se manifesta no limiar da consciência e que por isso é pré-pessoal. Uma linguagem que não se confina a um sentido lógico, estruturado, mas que se gera pela partilha de sentidos do sentir sensorial. A força do vínculo afetivo reside precisamente na intensidade do sentido sensorial como um sentido basilar, pré-pessoal, em estado potencial, o qual, por ser tão intrínseco, torna-se inconsciente, difícil de agarrar. Porém, na sua intensidade, proporciona uma percepção do corpo como movimento de transformação, intensifica o corpo animado pela relação corpo-mundo.

B) A segunda abordagem relaciona-se com transposição metafórica do sentido de afeto. Como verificamos previamente, o bailarino experiencia afeto como uma força vital de renovação de energias, sendo que esta experiência tem uma manifestação primária através do processo de respiração. Baseado no trabalho de Eugene Gendlin, Mark Johnson (1997, p. 168) sustenta que o nosso processo de cognição semântica é derivado de um modo afetivo de conceber sentido, um "felt sense [...] that exceeds our logical forms and patterns". Este modo afetivo é especialmente experienciado por meio da metáfora investigada por Steven Fesmire: "mental disquietude is inhibited breathing" (JOHNSON, 1997, p. 167), a qual mostra uma forte correlação entre tensão mental/emocional (associada a ansiedade e stress) e restrição da respiração. Ainda segundo Johnson (1997, p. 166), o nosso entendimento de tensão mental em termos da experiência física que se relaciona com a inibição da respiração pode ser exemplificado através das seguintes linhas metafóricas:

$\begin{array}{ll}\text { Breathing: } & \text { Mental Functioning: } \\ \text { Flow of air } & \text { Flow of ideas } \\ \text { Constricted air flow } & \text { Disrupted flow of ideas } \\ \text { Inhibited breathing } & \text { Mental disquietude } \\ \text { Restored air flow } & \text { Revived free-flow of ideas }\end{array}$

Este processo metafórico intrínseco ao nosso processo cognitivo revela claramente como o sentido sensorial emergente do afeto se torna transferido para o seu domínio emocional.

Johnson (1997, p. 167) expõe: "What cognitive semantics cannot capture in its generalizations, however, is the affective dimension of this experiential grounding of meaning"; no entanto, pode apontar para o experienciar do processo metafórico como via de construção de sentido. Acrescenta ainda que é urgente conhecer por meio dessa via, ou seja, aprender a pensar não apenas convencionalmente, mas sim experiencialmente. Pensar através de "embodied situations that are the locus of our experience, our thinking and our acting" (JOHNSON, p. 168). É, pois, ao incorporar o sentido de afeto que podemos compreender uma outra lógica de sentidos, em que o experienciar de sentidos sobrevém de uma índole paradoxal: um poder que vai ao encontro e contra a reprodução de uma estrutura e que é simultaneamente corpóreo e informe, basilar e indefinível. Contudo, entendemos 
que também é importante não nos deixarmos fixar pelo sentido experiencial, pois também precisamos aprender a pensar "back and forward across the shifting boundaries" (JOHNSON, p. 168).

Ao verificar que a qualidade vinculativa do afeto apresenta em si uma necessidade primária de sobrevivência, a psicologia vem certificar o caráter basilar do afeto associado a uma experiência somática crua. Desse modo, a noção de afeto torna-se evidenciada não como um conceito abstrato ou transcendental, mas como um conceito físico emergente, i.e., uma percepção que, apesar de difusa e de pertencer ao limiar da consciência, é uma percepção somática inata, intrínseca à experiência de corpo. O sentido de afeto manifesta-se, assim, como um sentido transversal de sobrevivência, um sentido que liga o sentir intensivo do corpo enquanto relação com o mundo, inerente ao processo orgânico de respiração e alimentação, com um sentido que se estende pela pele, delineando-se numa necessidade de contato, um sentido "entre-corpos".

\section{Informações sobre as autoras:}

\section{Cecília de Lima Teixeira}

(iD) https://orcid.org/0000-0002-5097-5602

Professora Convidada da Universidade de Lisboa - Faculdade de Motricidade Humana - licenciatura em Dança. Em paralelo, tem colaborado como Professora Convidada na Universidade Aberta - curso de Doutoramento em Digital-Media Arte. Desde 2014 integra o Editorial Advisory Board do Journal of Dance \& Somatic Practices. Doutorada (como bolseira da FCT) pela Universidade de Lisboa - FMH, na especialidade de Dança. Mestre em coreografia pela Faculdade de ArtesArtEZ (Holanda), com bolsa da Fundação Calouste Gulbenkian. Desenvolve a sua carreira como coreógrafa e bailarina desde 1999, trabalhando com diversos criadores europeus. Em 2001 tornou-se cofundadora da companhia Canvas Performing Art (Holanda), onde, durante seis anos, cocriou diversas performances interdisciplinares. Em paralelo, lecionou em diversas universidades, destacando-se: Amsterdam Faculty of Arts -Modern Dance e Arnhem ArtEZ Faculty of Arts (NL). Tem vindo a desenvolver investigação no Instituto de Etnomusicologia - Música e Dança (INET-md), no campo da relação da prática de dança com fenomenologia, ciências cognitivas e práticas somáticas, como também no âmbito da educação pela arte e da dança em expansão tecnológica. $\mathrm{O}$ seu trabalho tem vindo a ser publicado em revistas de circulação internacional e em vários encontros científicos.

\section{Gilead Marchezi Tavares}

\section{(iD) https://orcid.org/0000-0001-8168-3445}

\section{(9) http://lattes.cnpq.br/4587914500665718}

Possui graduação, mestrado e doutorado em Psicologia pela Universidade Federal do Espírito Santo. Pós-Doutorado no Programa de Pós-Graduação em Políticas Públicas e Formação Humana/UERJ (2011) e no Instituto de Etnomusicologia - Centro de Estudos em Música e Dança/FMH/Universidade de Lisboa (2018). É professora Associada do Departamento de Psicologia e do Programa de Pós-Graduação em Psicologia Institucional da Universidade Federal do Espírito Santo. Tem experiência na área de Psicologia, com ênfase em processos psicossociais da participação e da exclusão, processos de subjetivação e instituições sociais e processos cognitivos, atuando principalmente nos seguintes temas: exclusão social, direitos humanos, direitos da infância e juventude e processos de aprendizagem. Coorganizadora do livro "Cartas para pensar políticas de pesquisa em psicologia (2014) e Coautora dos livros "Juventude e risco: abrindo a sede ao meio no deserto das práticas de assistência social" (2017) e "Entre riscos e vínculos: a atuação da psicologia na assistência social” (2018).

\section{Contribuições das autoras:}

Cecília de Lima Teixeira foi responsável pela concepção, desenho, análise e interpretação dos dados. Gilead Tavares participou do desenho, revisão e aprovação da versão final do artigo.

\section{Como citar este artigo:}

\section{ABNT}

TEIXEIRA, Cecília de Lima; TAVARES; Gilead Marchezi. Corpo de Afetos: entre o apego emocional e o movimento dançado. Fractal: Revista de Psicologia, Niterói, v. 32, n. 1, p. 99-107, jan./ abr. 2020. https://doi.org/10.22409/1984-0292/v32i1/5741

APA

Teixeira, C. L., \& Tavares, G. M. (2020, Janeiro/Abril). Corpo de Afetos: entre o apego emocional e o movimento dançado. Fractal: Revista de Psicologia, 32(1), 99-107. doi: https://doi. org/10.22409/1984-0292/v32i1/5741

\section{Referências}

AINSWORTH, Mary D. Salter; BOWLBY, John. An ethological approach to personality development. American Psychologist, v. 4, n. 46, p. 333-341, 1991.

ANDRADE, Carlos Drummond. Fazendeiros do Ar. São Paulo: Companhia das Letras, 2012.

BOWLBY, John. Attachment and loss (1907). London: Hogarth, 1969. v. 1.

BRONFENBRENNER, Urie; EVANS, Gary W. Developmental science in the 21st century: emerging questions, theoretical models, research designs and empirical findings. Social development, v. 1, n. 9, p. 115-125, 2000.

DAMÁSIO, António. The feeling of what happens: body and emotion in the making of consciousness. London: Vintage Books, 2000.

DAMÁSIO, António. Ao encontro de Espinosa. Lisboa: Publicações Europa América, 2003.

DAMÁSIO, António. O livro da consciência: a construção do cérebro consciente. Lisboa: Circulo de Leitores, 2010.

DEMOS, Virginia E. (Ed.). Exploring affect: the selected writings of Silvan S. Tomkins. Cambridge: University Press, 1995.

EDELMAN, Gerald M. Biologia da Consciência: as raízes do pensamento. Lisboa: Instituto Piaget, 1992.

ESPINOSA, Baruch de. Pensamentos metafísicos. Tratado da correção do intelecto. Ética. Tratado político. Correspondência. 3. ed. São Paulo: Abril Cultural, 1983. (Coleção Os pensadores).

FRALEY, R. Chris; GILLATH, Omri; KARANTZAS, Gery C. Adult attachment: a concise introduction to theory and

research. New York: Elsevier Academic Press, 2016.

GIBBS Jr., Raymond W. Embodiment and Cognitive Science. Cambridge UK: Cambridge University Press, 2005.

GIBSON, James J. The senses considered as perceptual systems. Connecticut: Greenwood Press, 1966.

HARLOW Harry F. The nature of love. American Psychologist, v. 12, n. 13, p. $673-685,1958$.

HARLOW, Harry F.; ZIMMERMANN, Robert R. Affectional responses in the infant monkey. Science, v. 130, n. 3373, p. 421432,1959 
HORTA, Rui. O corpo em constante aprendizagem e esquecimento - entrevista concedida a Cláudia Galhós. In: TNSJ et al. (Ed.). Rui Horta x Quatro. Porto: Centro de Edições do TNSJ, 2006.

JOHNSON, Mark. The body in the mind: the bodily basis of meaning, imagination, and reason. Chicago: University of Chicago Press, 1990.

JOHNSON, Mark. Embodied meaning and cognitive science. In: LEVIN, David M. (Ed.). Language beyond postmodernism: saying and thinking in gendlin's philosophy. USA: Evanston Northwestern University Press, 1997. p. 148-175.

LAKOFF, George; JOHNSON, Mark. Conceptual metaphor in everyday language. The Journal of Philosophy, v. 8, n. 77, p. 453-486, 1980.

LAKOFF, George; JOHNSON, Mark. Philosophy in the flesh: the embodied mind and its challenge to western thought. New York: Basic Books, 1999.

LAKOFF, George; JOHNSON, Mark. Metaphors we live by. Chicago and London: University of Chicago Press, 2003.

LIMA, Cecília de. Trans-meaning - dance as an embodied technology of perception. Journal of Dance and Somatic Practices, v. 1, n. 5, p.17-30, 2013.

MASSUMI, Brian. Parables for the virtual: movement, affect, sensation. London: Duke University Press, 2002.

MANTERO, Vera; GIL, José. A riqueza de espírito, movimento intenso. In: LEPECKI, André (Ed.). Theaterschrift extra intensificação: performance contemporânea portuguesa. Lisboa: Cotovia, 1998. p. 33-60.

MATURANA, Humbert R.; VARELA, Francisco J. Autopoiesis and cognition: the realization of the living. Dordrecht: D. Reidel Publishing Company, 1980.

PONTES, F. et al. Teoria do apego: elementos para uma concepção sistémica da vinculação humana. Aletheia, n. 26, 67-79. 2007. Disponível em: https://www.redalyc.org/articulo. oa? $\mathrm{id}=115013567007$. Acesso em: 21 out. 2016.

PSYCHIATRIC GLOSSARY. Disponível em: http://www. priory.com/gloss.htm. Aceso em: 5 mar. 2014.

SAPOLSKY, Robert. Are humans just another primate? Conferência [online]. 2 mar. 2011. Disponível em: https:/ www.youtube.com/watch?v=YWZAL64E0DI. Acesso em: 1 jul. 2015.

SEIGWORTH, Gregory J. From affection to soul. In: STIVALE, Charles J. (Ed). Gilles Deleuze key concepts. Montreal \& Kingston Ithaca: McGill Queen's University Press, 2005. p. 159-169.

SHOUSE, Eric. Feeling, Emotion, Affect. M/C Journal, v. 6, n. 8, 2005. Disponível em: http://journal.media-culture.org. au/0512/03-shouse.php. Acesso em: 16 maio 2012.

SIMONDON, Gilbert. L'individuation psychique et collective. Paris: Flammarion, 2007.

TAVARES, Gonçalo M. Breves notas sobre a ciência. Lisboa: Relógio d'Água, 2006.
TRISTÃO, Valeska Campos. (Com) viver e (com) fiar uma rede quente na experiência sensivel de vinculação afetiva: uma análise das práticas de acolhimento infanto-juvenil no município de Vitória/ES. 2015. 121f. Dissertação (Mestrado em Psicologia Institucional) - Programa de Pós-Graduação em Psicologia Institucional, Universidade Federal do Espírito Santo, Vitória, 2015. 